\title{
A rare cause of childhood renal cysts: Xp11.2 translocation renal cell carcinoma
}

\author{
Hakan Taşkınlar, MD; Dinçer Avlan, MD; Çağlar Çıtak, MD; Ayşe Polat, MD; Ali Naycı, MD \\ Pediatric Surgery Department, Mersin University Hospital, Mersin, Turkey
}

Cite as: Can Urol Assoc J 2015;9(1-2):E36-8. http://dx.doi.org/10.5489/cuaj.2321 Published online January 12, 2015.

\section{Abstract}

Pediatric renal cysts are rare, usually asymptomatic and incidentally detected in children. Cyst associated renal cell carcinoma (RCC) or cystic RCC is extremely rare in children. Bosniak classification system has been accepted for the management of cystic renal masses. Xp11.2 translocation RCC is a recently classified distinct subtype and usually affects children and adolescents. We report the case of a 10-year-old girl with Xp11.2 translocation RCC from a cyst of the right kidney.

\section{Introduction}

Renal cell carcinoma (RCC) in children accounts for $2.2 \%$ to $4.3 \%$ of all reported pediatric renal malignant tumours; the incidence of RCC is estimated at 0.01/100 000 population. ${ }^{1}$ Cyst-associated RCC or cystic RCC is extremely rare. ${ }^{2}$ In clinical practice, it is difficult to preoperatively determine whether a complicated cyst is malignant. The translocations involving chromosome Xp11.2, the locus of the TFE3 gene in a large percentage of pediatric RCC, has been showed in recent years. ${ }^{3,4}$ Xp11.2 translocation RCC includes at least one-third of pediatric RCC. ${ }^{5}$ They are characterized by various translocations involving chromosome Xp11.2, all resulting in gene fusions involving the transcription factor E3 (TFE3). ${ }^{6}$ We report a 10-year-old girl with Xp11.2 translocation cystic RCC and discuss its genetics and clinicopathologic features.

\section{Case report}

A 10-year-old girl, who was known to be urinary continent, was admitted to a prior hospital with complaints of enuresis diurnal for 2 weeks. An incidental $4.5 \times 4-\mathrm{cm}$ heterogeneous cystic-nodular lesion in the upper pole of the right kidney was detected on her abdominal ultrasonography. She was referred to our department with the diagnosis of renal cyst for further investigation and treatment. She had no underlying predisposing conditions or syndromes, including no history of trauma, chronic renal disease, and tuberous sclerosis, as well as no family history of renal cysts.

A repeated ultrasonography revealed a $23 \times 19-\mathrm{mm}$ cystic lesion with internal echogenities and a $25 \times 19$-mm heterogeneous hyperechogenic area with milimetric calcifications close to the cystic lesion in the upper pole of right kidney. Intravenous pyelography, performed to rule out focal pelvicalyceal dilatation, revealed a focal space-occupying lesion with a mild displacement of upper pole calyces. A contrastenhanced computed tomography (CT) scan confirmed the ultrasonography findings (Fig. 1). Surgical exploration was performed for a suspected malignancy. A cystic mass and a solid mass close to cyst in the upper pole of right kidney were noticed after opening the Gerota's fascia. There was no involvement of the perirenal tissues such as Gerota's fascia or renal sinus fat. Due to the heterogeneous macroscopic appearance of the lesion with solid, necrotic and calcified components, a frozen biopsy was performed. Radical nephrectomy was performed because of the malignant findings in the frozen specimen and unclear surgical margins between the normal renal parenchyma and the tumour. Histologically, the tumour exhibit nested, alveolar to papillary growth pattern separated by thin branching fibro-vascular septa. Tumour cells contained sharply demarcated mostly voluminous clear focally eosinophylic cytoplasm and central round vesicular nuclei with rare mitotic figures (Fig. 2). Psammomatous calcification and periodic acid-Schiff stain positive hyaline basement membrane material were observed in the tumour stroma (Fig. 3). The tumour was restricted in the renal capsule without invasion to the fat tissue outside the renal capsule and peripelvic fatty renal tissue. Immunohistochemically neoplastic cells were positive for CD10, transcription factor-E3 (TFE3) and cathepsin k. Microscopic and immunohistochemical examinations revealed this case as Xp11.2 translocation RCC. The patient did well after surgery without no recurrence at the 1-year follow-up. 


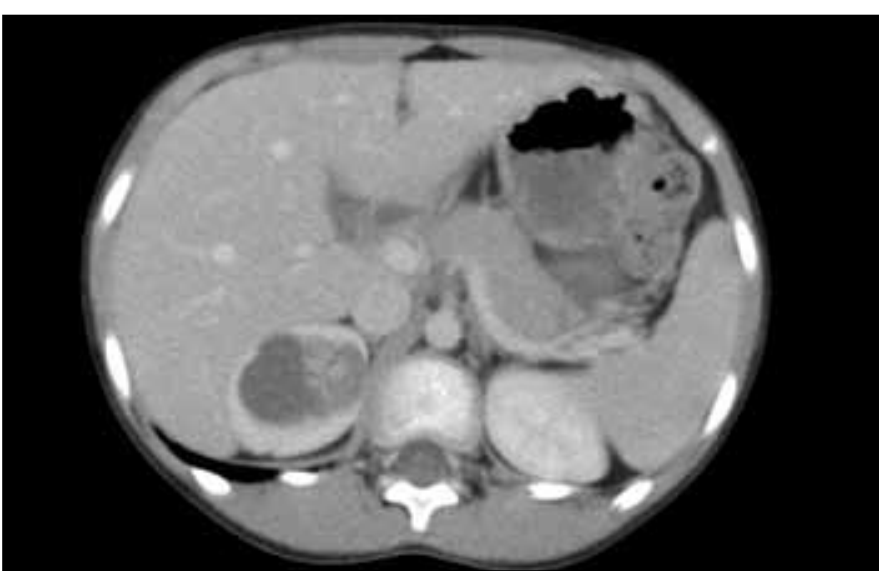

Fig. 1. Computed tomography showing a heterogeneous cystic lesion with milimetric calcifications in the upper pole right kidney.

\section{Discussion}

Simple or complicated renal cysts are rare in children. Simple renal cysts are usually asymptomatic, so they are incidentally detected by ultrasonography performed for suspected urinary tract infection or for other reasons unrelated to the urinary tract. ${ }^{7}$ However, the complicated renal cysts associated with solid internal components or nodular areas have a malignant potential probably. The Bosniak classification system has been accepted as a method for diagnosis and determining the management of cystic renal masses, which was designed to analyze the morphology of cystic masses based on solely on CT finding. ${ }^{8}$ Wallis and colleagues modified the Bosniak classification of pediatric renal cysts for the radiographic evaluation of complex renal cysts in children. ${ }^{9}$ According to this classification, Bosniak category III and IV describe the cystic mass association with solid internal component or nodular areas, irregular calcifications detected on ultrasound and CT. Furthermore, Wallis and colleagues presented a series of 39 patients; of the 5 patients with Bosniak III or IV cysts, 2 had RCC. The authors also point out that Bosniak III and IV renal cysts may have malignant potential. ${ }^{9}$ In the present case, solid components and calcifications of the lesion were detected by ultrasound and CT. According to these findings, surgery was decided for our patient.

A significant proportion of pediatric RCC shows translocations involving chromosome Xp11.2, resulting in a fusion of the TFE3 gene to a variety of targets. This translocation is also shown in the patients as a secondary malignancy after the treatment of neuroblastoma., ${ }^{3,5,10}$ Xp11.2 translocation RCCs demonstrate nuclear immunohistochemical labeling for TFE3. Translocations involving TFE3 induce overexpression of this protein and can be specifically identified by immunohistochemistry. ${ }^{6} \mathrm{Wu}$ and colleagues reported that most patients with Xp11.2 translocation RCC present at an advanced stage and recommended that high-grade RCC in children and young adults should be tested for TFE3 immu-

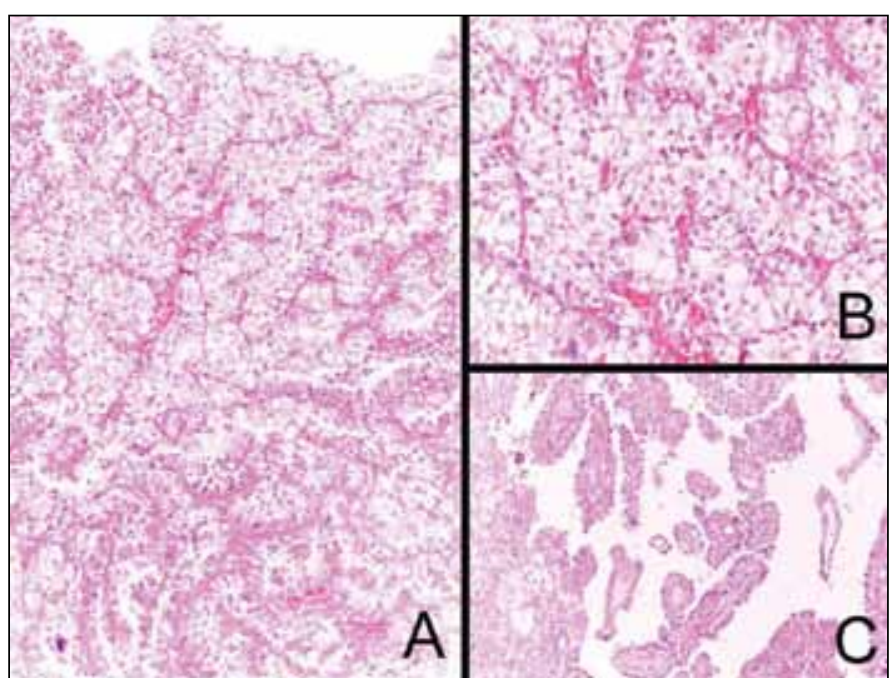

Fig. 2. Histological findings (Hematoxylin and eosin staining). A: The tumour shows nested to alveolar growth pattern separated thin branching fibrovascular septa. B: On higher power view, we see a clear voluminous cytoplasm by distinct cell border tumour cells lined fibrovascular septa $(\times 400)$. C: Papillary growth pattern in tumour was also detected $(\times 100)$.

nohistochemistry to rule out Xp11.2 translocation RCC. ${ }^{4}$ Our case showed strong nuclear immunoreactivity for TFE3, which indicates that it is an Xp11.2 translocation RCC. Xp11.2 translocation RCCs include low expression of cytokeratin and vimentin, ${ }^{11}$ and these are commonly expressed by 2 markers in adult RCC. In our case, the tumour was positive for cathepsin $\mathrm{K}$ apart from the TFE3 overexpression.

To date, there is no commonly accepted histologic classification system for pediatric RCCs. Renshaw and colleagues reported that the most distinctive histologic characteristic of the pediatric RCCs is papillary architecture. ${ }^{12}$ Xp11.2 translocation RCCs typically have nested or papillary architecture and are composed of cells with voluminous, clear or eosinophylic cytoplasm; however they are morphologically heterogeneous. ${ }^{11}$ Argani and Ladanyi suggested that histologic

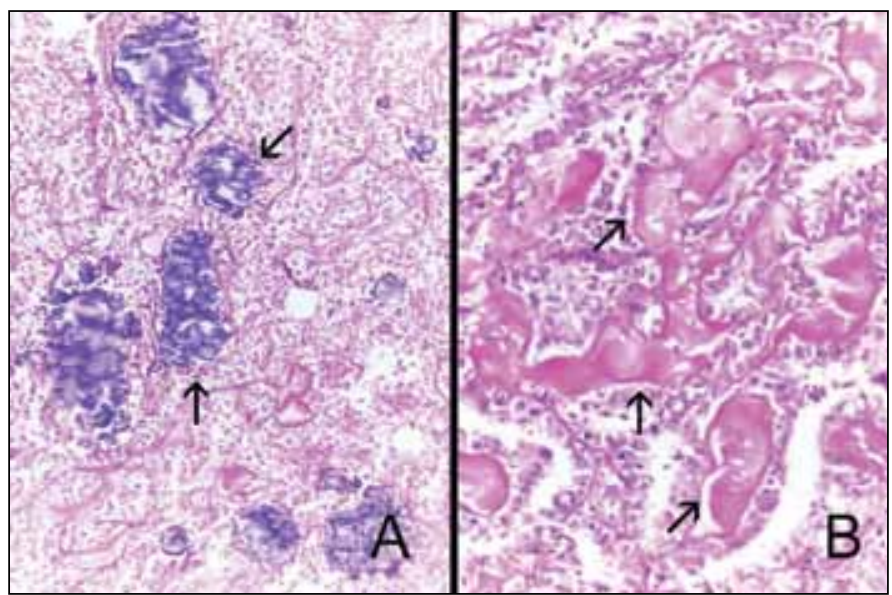

Fig. 3. Psammomatous calcification (A) and periodic acid-Schiff stain positive hyaline bodies (B) were seen in the tumour stroma (arrowed) $(\times 100)$. 
variants of Xp11.2 translocation carcinomas were associated with specific chromosome translocation. The papillary RCC TFE3 variant is generally composed of a mix of intermediated sized, clear and eosinophylic cells, arranged in a predominantly nested pattern with small foci of a papillary pattern. ${ }^{11}$ Our case has the typical histopathological characteristics of Xp11.2 RCCs.

Although, surgical excision is standard treatment for RCC, debate continues about the modality of the surgical approach. Partial nephrectomy or nephron-sparing surgery is generally preferred in adults, but, there are few reports about experience of pediatric RCC patients with a favourable outcome after nephron-sparing surgery. ${ }^{13,14}$ Cook and colleagues reported a $100 \%$ disease-free survival rate in 5 pediatric patients who underwent open partial nephrectomy for RCC patients with a tumour diameter of $4 \mathrm{~cm}$ or less with localization to 1 pole and clear margins to the normal kidney parenchyma. Our patient had 4.5-cm solid and cystic mass in the upper pole and the margin between normal parenchyma and tumour was unclear. Therefore, we performed total nephrectomy in our case. Postoperatively, adjuvant radiotherapy and chemotherapy are recommended for higher grade tumours. Although the beneficial effects of immunotherapy with high dose IL-2 have been reported,,$^{15}$ the effects of this treatment modality are unclear. On the other hand, some patients with Xp11.2 translocation RCC have received immunotherapy because, until recently, immunotherapy has been the only standard treatment for patients with advanced stage conventional clear cell RCC. However, recent gene expression profiling data suggest that Xp11.2 translocation RCCs may not respond to immunotherapy directed toward conventional clear cell RCCs. ${ }^{16}$ Currently, tyrosine kinase inhibitors have been considered for the treatment because of the significant overexpression of MET tyrosine kinase in ASPL/TFE3 translocation tumours. Hence, MET tyrosine kinase may be a potential therapeutic target in Xp11.2 translocation RCCs. ${ }^{17}$

\section{Conclusion}

Xp11.2 translocation RCCs occur primarily in children and young adults and can be rather indolent even when diagnosed at advanced stages. TFE3 fusion protein expression by immunohistochemistry can be an easy and useful technique to identify this tumour. Nuclear immunohistochemical labelling for TFE3 is used for research, but is not yet used clinically. Additionally, Xp11.2 translocation RCCs have clinicopathologic heterogeneity in children, but the clinical and molecular basis for this heterogeneity remains to be elucidated.

Acknowledgement: The authors would like to thank to Mr. Pedram Argani, MD, for contributing to the immunohistochemical studies.
Competing interests: Authors declare no competing financial or personal interests.

This paper has been peer-reviewed.

\section{References}

1. Silberstein J, Grabowski J, Saltzstein SL, et al. Renal cell carcinoma in the pediatric population: Results from the California cancer registry. Pediatr Blood Cancer 2009;52:237-41. http://dx.doi.org/10.1002/ pbc.21779

2. Sausville JE, Hernandez D, Argani P, et al. Pediatric renal cell carcinoma. J Pediatr Urol 2009;5:308-14. http://dx.doi.org/10.1016/i.jpurol.2009.04.007

3. Argani P, Ladanyi M. Renal cell carcinomas associated with Xp11.2 translocations/TFE3 gene fusions. In: Eble JN, Sauter G, Ebstein II, Sesterhenn IA, editors. World Health Organization Classification of Tumors: Pathology and genetics of fumors of the urinary system and male genital organs. Lyon: IARC, 2004;37-8.

4. Wu A, Kunju $L P$, Cheng $L$, et al. Renal cell carcinoma in children and young adults: Analysis of clinicopathological, immunohistochemical and molecular characteristics with an emphasis on the spectrum of $X_{p} 11.2$ translocation-associated and unusual clear cell subtypes. Histopathology 2008;53:533-44. http://dx.doi. org/10.1111/.i.1365-2559.2008.03151.x

5. Argani $P$, Ladnyi M. Distinctive neoplasms characterized by specific chromosomal translocations comprise a significant proportion of pediatric renal cell carcinomas. Pathology 2003;3:492-8. http://dx.doi.org/ 10.1080/00313020310001619901

6. Argani $P$, Lal P, Hutchinson B, et al. Aberrant nuclear immunoreactivity for TFE3 in neoplasms with TFE3 gene fusions: A sensitive and specific immunohistochemical assay. Am I Surg Pathol 2003;27:70-1. http://dx.doi.org/10.1097/00000478-200306000-00005

7. Whelan TF. Guidelines on the management of renal cyst disease. Can Urol Assoc J 2010;4:98-9. http:// dx.doi.org/10.5489/cuaj.10023

8. Israael GM, Bosniak MA. An update of the Bosniak renal cyst classification system. Urology 2005;66:4848. http://dx.doi.org/10.1016/j.urology.2005.04.003

9. Wallis MC, Lorenzo AJ, Farhat WA, et al. Risk assessment of incidentally detected complex renal cysts in children: Potential role for a modification of the Bosniak classification. J Urol 2008;180:317-21. http:// dx.doi.org/10.1016/i.juro.2008.03.063

10. Hedgepeth RC, Zhou M, Ross J. Rapid development of metastatic Xp 11 translocation renal cell carcinoma in a girl treated for neuroblastoma. J Pediatr Hematol Oncol 2009;31:602-4. http://dx.doi.org/10.1097/ MPH.0b013e3181acd981

11. Argani P, Ladanyi M. Translocation carcinomas of the kidney. Clin Lab Med 2005;25:363-78. http:// dx.doi.org/10.1016/i.cll.2005.01.008

12. Renshaw AA, Granter SR, Fletcher JA, et al. Renal cell carcinomas in children and young adults: Increased incidence of papillary architecture and unique subtypes. Am I Surg Pathol 1999;23:795-802. http:// dx.doi.org/10.1097/00000478-199907000-00007

13. Cook A, Lorenzo A J, Salle IL, et al. Pediatric renal cell carcinoma: Single institution 25-year case series and initial experience with partial nephrectomy. J Urol 2006;175:1456-60. http://dx.doi.org/10.1016/ S0022-5347(05)00671-3

14. Selle B, Furthwangler $R$, Graf $N$, et al. Population-based study of renal cell carcinoma in children in Germany, 1980-2005: More frequently localized tumors and underlying disorders compared with adult counterparts. Cancer 2006;107:2906-14. http://dx.doi.org/10.1002/cncr.22346

15. Baver $M$, Reaman $G H$, Hank JA, et al. A phase II trial of human recombinant interleukin-2 administered as a 4-day continuous infusion for children with refractory neuroblastoma, non-Hodgkin's lymphoma, sarcoma, renal cell carcinoma, and malignant melanoma. A Children's Cancer Group Study. Cancer 1995;75:2959-65. http://dx.doi.org/10.1002/1097-0142(19950615)75:12<2959::AIDCNCR2820751225>3.0.C0;2-R

16. Armah HB, Parvani AV. Xp 11.2 Translocation renal cell carcinoma. Arch Pathol Lab Med 2010;134:124-9.

17. Tsuda M, Davis IJ, Argani P, et al. TFE3 fusions activate MET signaling by transcriptional up-regulation, defining another class of tumors as candidates for therapeutic MET inhibition. Cancer Res 2007;7:919-29. http://dx.doi.org/10.1158/0008-5472.CAN-06-2855

Correspondence: Dr. Hakan Taşkinlar, C,iftlikköy Kampusu 33343 Yenisehir/Mersin, Turkey; hakantaskinlar@gmail.com 